\title{
Simulation Optimization Design on Vehicle Disk Brake
}

\author{
Pengfei Duan ${ }^{1, a}$ \\ ${ }^{1}$ Dept. of Equipment Support, Bengbu Automobile NCO Academy, Bengbu 233011, China \\ aduanpengfei202@sina.com
}

Keywords: Disk brake, Optimization design, Simulation

\begin{abstract}
The braking performance is one of the most important active safety performances of vehicle, which plays a key role in the traffic safety. It is necessary to research on braking efficiency and it becomes a hotspot to express the braking performance scientifically and rationally. To improve braking capability and efficiency of vehicle disk brake, a multi-objective optimization model with the lowest braking temperature and the largest braking torque as the objective function was proposed. The model was on the basis of property indexes and restraints needed for disk brake designing. The example to verify its fitness was provided and Genetic Algorithm (GA) in Matlab optimization toolbox was used for solving ideal result.
\end{abstract}

\section{Introduction}

Design of vehicle disk brake should be considered comprehensively and optimized to avoid brake deterioration caused by temperature rising in the practical application process. Disk brake is widely used in engineering machinery and various automobiles for its advantages of simple and compact structure, braking capability, good thermal and water stabilities. Given the same braking torque, disk brake is smaller in size and weight than drum brake. According to related materials, the accidents caused by brake system failure accounted for $45 \%$ in that caused by problems of vehicle itself. Furthermore, long braking distance and brake slip often leads to fatal accidents in the emergency braking, which indicates key role of rake to ensure mechanical device security. The vehicle braking system aims at grasping vehicle start and stop, controlling speed, dealing with incidents and maintaining vehicle in accordance with needs of drivers. Its high quality and excellent performance are important guarantee for vehicle safety. Thus, all newly designed or modified vehicles should carry out brake performance tests. It is of significance to improve vehicle braking performance, design and manufacture level, which has increasingly become an important topic in the field of vehicle researches [1-3].

The existing researches just uses the shortest braking time and the thinnest braking disc as the objective function, but the weighting factors of sub-objectives not been normalized, resulting in the differences in magnitudes of sub-objectives and in turn affects the optimization. It will lead to bad braking effect because of the heat of friction plate, and even the brake disc will crack taking the shortest braking time as objective function but not take the rising temperature of brake into account in practical applications. To improve braking capability and efficiency of disk brake, a multi-objective optimization model with the lowest braking temperature and the largest braking torque as the objective function is designed in this research, which is based on the analysis of property index and restraint that designing a disk brake requires, then genetic algorithms of MATLAB optimization toolbox are used for optimization solution so as to arrive at good results. The paper is organized as follows: section 2 provides related works; section 3 mainly perform mathematic calculation related to disk brake design; section 4 proposes the optimization design model; section 5 gives design example; section 6 concludes our work.

\section{Related Works}


The development of vehicle braking technology is always around the basic function and security performance of braking system. It is of importance to research brake and its performance targeting at developing new mode with low cost and high repetition utilization. Traditional design methods need large amount of test and repeated changes, so it is extremely difficult for product development. With the continuous development of simulation technology in recent years, the new development mode that analyze brake system performance with various modeling methods attracted more and more attention. Qin et al carried on multi-objective fuzzy optimization design on disc brakes on the car [4]. Ding et al addressed to fuzzy optimization design on disk brake of construction machinery [5]. The simulation methods to analyze braking process mainly based on heat conversion in the automobile braking process. The brake model was established with in Matlab/Simulink. The obtained brake distance was compared with known data to arrive at good result. The ABS combined simulation model is constructed which consists of ABS mechanical dynamics model for cars simulation using ADAMS software and ABS control simulation model using Matlab/Simulink. software.The thresholds of ABS regulated parameters are determined using Matlab software [6]. The Matlab and ADAMS were also utilized for co-simulation to establish integrated mechatronic system model, so as to complete brake performance simulation test in the virtual environment and arrived at good result [7]. The co-simulation technology was used for fuzzy control of semi-active suspension system, namely damping-adjustable shock absorber model is built with EASYS software, and mechanism model of suspension system is built with ADAMS software and control model based on fuzzy arithmetic is built with Matlab software, so as to reduce vehicle vibration and improve vehicle ride comfort characteristics. The paper mainly emphasizes on performance computation and optimization of disk brake.

\section{Disk Brake Design Calculation}

Brake torque calculation. In calculation, it is considered that friction surface of pads get in touch with brake disc, and that unit pressure $p$ is evenly distributed, as shown in the Fig. 1.

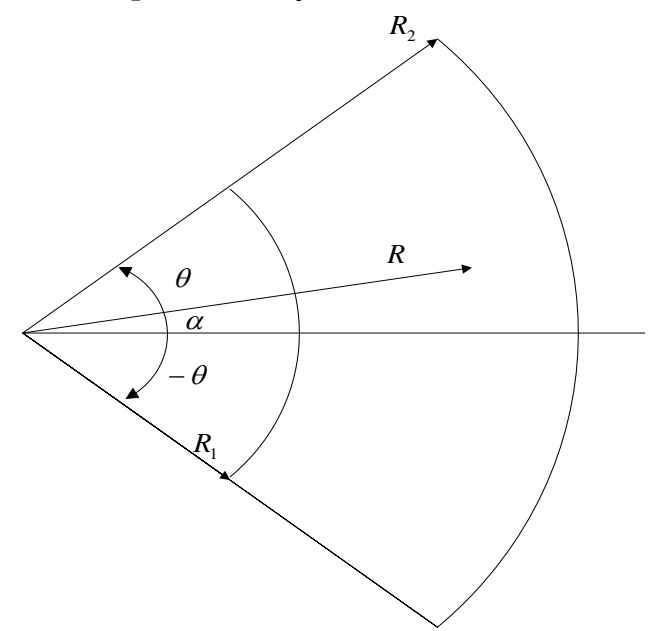

Fig. 1 Brake torque calculation of disc brake

Take an area of $R d \alpha d R$ from friction surface of pads as rectangular infinitesimal. The resulting brake torque for brake disc center is $d M_{f}=f \cdot p R d \alpha d R \cdot R, f$ is the friction factor between friction pads and brake disc.

Obviously, brake torque of friction pad on one side for brake disc center is $\frac{M_{f}}{2}=\int_{-\theta}^{\theta} \int_{R_{1}}^{R_{2}} f p R^{2} d \alpha d R=\frac{2}{3} f p\left(R_{2}^{3}-R_{1}^{3}\right) \theta, R_{1}, R_{2}$ are the inner and outer radius of brake pad; $\theta$ is a half of the corner of brake pad.

So, the total brake torque of disk brake $M_{f}$ is:

$$
M_{f}=\frac{4}{3} f p\left(R_{2}^{3}-R_{1}^{3}\right) \theta \text {. }
$$


Set liquid pressure of the brake cylinder as $p_{0}$, so the unit pressure $p$ between friction surface of brake pad and brake disc contact area is:

$$
p A=p_{0} \frac{1}{4} \pi d^{2},
$$

$d$ is the role diameter of brake cylinder piston; $A$ is the effective area of friction pad on one side, $A=\frac{2 \theta}{2 \pi} \cdot \pi\left(R_{2}^{2}-R_{1}^{2}\right)=\theta\left(R_{2}^{2}-R_{1}^{2}\right)$.

Take the above equation into (2), and the unit pressure $p$ between friction surface of and brake disc contact area is:

$$
p=\frac{2 \pi d^{2}}{\theta\left(R_{2}^{2}-R_{1}^{2}\right)} P_{0} .
$$

Take (3) into (1), so the brake torque that two sides of friction pads produce is

$$
M_{f}=2 \cdot \frac{1}{3} f p_{0} \frac{\pi}{4} d^{2} \frac{\left(R_{2}^{3}-R_{1}^{3}\right)}{\left(R_{2}^{2}-R_{1}^{2}\right)}=\frac{1}{6} f \pi d^{2} \frac{\left(R_{2}^{3}-R_{1}^{3}\right)}{\left(R_{2}^{2}-R_{1}^{2}\right)} p_{0} .
$$

Set $R_{e}=\frac{\left(R_{2}^{3}-R_{1}^{3}\right)}{\left(R_{2}^{2}-R_{1}^{2}\right)}$ as the effective radius of disc brake.

Wear characteristics calculation. The working process of friction type of brake can be understood as a process of converting mechanic energy into heat energy. Most of the kinetic energy of automobile is consumed by brake within a short time, while the rest of the kinetic energy can be consumed by resistance from tire rolling and air. So brake is heated up, which is called energy load of brake.

Energy load of brake is usually evaluated by using specific energy dissipation rate that physically means the energy consumed by unit area of friction plate in unit of time with the international unit of $W / m^{2}$. The specific energy dissipation rate of single front wheel brake is defined as $e_{f}=\frac{1}{2} \frac{\beta \cdot \delta \cdot m v_{1}^{2}}{2 t A_{f}}$. Where, $\beta$ is the distribution ration of front and rear braking force; $\delta \cdot m$ is the total vehicle mass including conversion rotating mass; $A_{f}$ is the affected area of front wheel friction pad; $t$ is braking duration. When strong braking in an emergency happens, braking deceleration $j$ is taken as constant, $t=\frac{v_{1}-v_{2}}{j}$; setting $j$ as $0.6 \mathrm{~g}$.

The specific energy dissipation rate of disk brake is much bigger than drum brake, but it is better not to exceed $6 \mathrm{~W} / \mathrm{mm}^{2}$. Otherwise, friction pad will be worn more quickly, and brake disc will also crack.

Unit pressure calculation. To guarantee that friction pad is resistant to wearing and can be used for a long time, the unit pressure between friction pad and brake disc must be limited within a certain range. Set the normal pressure that one side friction pad of front brake gets as $N$, and unit pressure $p$ is evenly distributed. So $p=\frac{N}{A_{f}}$, total brake torque of front brake (two friction pads) is $M_{f}=2 f N R_{e}$.

Meanwhile, the ground brake force of front axle has the relation: $\frac{M_{f}}{r}=\beta m j$, So, $p=\frac{\beta m j r}{2 f R_{e} A_{f}}<[p]=2 M p a$.

Heat capacity and temperature increase calculation. The working process of friction type of brake can be understood as a process of converting mechanic energy into heat energy. Most of the kinetic energy of automobile is consumed by brake within a short time, while the rest of the kinetic energy can be consumed by resistance from tire rolling and air. So brake is heated up, which is called 
energy load of brake. In engineering, $\alpha$ can be used to express the proportion of kinetic energy that brake absorbs in the process, with $\alpha$ set as $0.9 \sim 0.93$.

Friction pad is usually made of non-metallic materials, so it has a poor property in heat conduction. Much of the heat is absorbed by metal brake disc. The more energy load of brake, the more seriously friction plate is worn. Therefore, the heat capacity and temperature increase of brake must be calculated. According to the theory of conservation of energy, kinetic energy before braking is $E=\frac{1}{2} m v_{1}^{2}$.

Temperature increase of checking brake disc is $c_{d} m_{d} \Delta t>\alpha E$. In this formula, $c_{d}$ is the specific heat capacity of brake disc metal material, taking $482 \mathrm{~J}(\mathrm{~kg} \cdot \mathrm{K})$ of cast iron, $880 \mathrm{~J}(\mathrm{~kg} \cdot \mathrm{K})$ of aluminum. The $m_{d}$ is the weight of brake disc; $v_{1}$ is the speed of brake disc; $\Delta t$ is the temperature increase of brake disc. Usually, braking should be completed when the initial velocity of braking reaches $30 \mathrm{~km} / \mathrm{h}$, with the temperature increase not more than 15 degrees Celsius. It is difficult to calculate the weight of brake disc at the beginning of design, so it can be seen as regularly shaped discoid parts. The weight of brake disc $m_{d}$ can be calculated approximately as $m_{d}=\rho_{d} \frac{1}{4} \pi D^{2} b$. In this formula, $\rho_{d}$ is the density of brake disc material, set as $7513 \mathrm{~kg} / \mathrm{m}^{3}$; $D$ is the outer diameter of brake disc and $b$ is the thickness of brake disc.

\section{Optimization Model Establishment}

Objective function. Brake torque is the key target parameter to the function of brake. Therefore, in much of the research literature, biggest brake torque is set as optimization objective function. According to engineering experience, special attention should be paid to the controlling of temperature increase of brake disc while considering the biggest brake torque. Otherwise, the service time of brake will be greatly reduced. In this paper, biggest brake torque and smallest temperature increase of brake disc are set as objective function to achieve optimization.

Based on the above theoretical analysis, to get the biggest brake torque total brake torque of a disc brake is:

$$
\max M_{f}=\max \left[\frac{1}{6} f \pi d^{2} \frac{\left(R_{2}^{3}-R_{1}^{3}\right)}{\left(R_{2}^{2}-R_{1}^{2}\right)} p_{0}\right] .
$$

To get the smallest temperature increase of brake, we can get the following result from $c_{d} m_{d} \Delta t=\alpha E$ :

$$
\min \Delta t=\frac{\alpha E}{c_{d} m_{d}}=\min \left[\frac{\alpha\left(m v_{1}^{2}\right)}{2 c_{d} m_{d}}\right] .
$$

The two objective functions belong to two different classes, getting the biggest for the former but the smallest for the latter. Thus, "multiplication and division" can be used to make a balance:

$$
\min \operatorname{obj}(x)=\min \frac{M_{f}}{\Delta t} \text {. }
$$

Designing variable. After studying structures and property parameters related to disc brake, set the following seven parameters as designing variables.

$$
X=\left[\begin{array}{lllllll}
x_{1} & x_{2} & x_{3} & x_{4} & x_{5} & x_{6} & x_{7}
\end{array}\right]=\left[\begin{array}{lllllll}
D & b & d & p_{0} & R_{1} & R_{2} & \theta
\end{array}\right]
$$

The $D$ is the outer diameter of brake disc; $b$ is the thickness of brake disc; $d$ is the diameter of brake cylinder; $p_{0}$ is oil pressure; $R_{1}$ is the inner diameter of friction pad; $R_{2}$ is outer diameter of friction pad; $\theta$ is the central angle of friction pad.

Constraint function. The constraint on properties includes the following parts. The first is constraint on unit pressure between friction pad and brake disc. The second one is constraint on temperature increase of brake. The last one is constraint on specific energy dissipation rate. 
Above three constraints will not be discussed at length, since detailed derivation about them has already been made in the above analysis.

The constraint on brake torque: in order to prevent wheel lock, braking force should be smaller than traction on ground. For example:

$$
\lambda T_{f}<\frac{1}{2} \mu \mathrm{mg} \beta \cdot r
$$

The constraint on brake oil pressure: the highest oil pressure of hydraulic brake lines is generally not more than 12Mpa.

$p_{0}<[p]$

The constraint on structural parameters of disc brake:

$D<0.78 D_{h}$;

$R_{2}+0.002-\frac{D}{2}<0$;

$D_{g}+0.004-R_{1}<0$;

$1.27<\frac{R_{2}}{R_{1}}<1.63$.

\section{Optimization Design Example}

Set $D_{h}=0.316, D_{g}=0.13 \mathrm{~m}, v_{1}=100 \mathrm{~km} / \mathrm{h}, \lambda=1.16, r=0.407 \mathrm{~m}, e=6 \times 10^{-3} \mathrm{~W} / \mathrm{m}^{2}, \mu=0.66$, $f=0.37, \rho=7499 \mathrm{~kg} / \mathrm{m}^{3}$. 1.

The initial values of design variables of disc brake structure and properties are shown in the Table

Table 1 The initial values of design variables of disc brake structure and properties

\begin{tabular}{ccccccc}
\hline$D$ & $b$ & $d$ & $\rho_{0}$ & $R_{1}$ & $R_{2}$ & $\theta$ \\
\hline $0.264 m$ & $0.0143 m$ & $0.0505 m$ & $3.1 M P a$ & $0.061 \mathrm{~m}$ & $0.125 \mathrm{~m}$ & $60{ }^{\circ} \mathrm{C}$ \\
\hline
\end{tabular}

According to the theoretical analysis, the optimizer can be written. We can get the following results if the main function optimization is operated.

Disc brake torque before optimization is $128.71 \mathrm{~N} \cdot \mathrm{m}$;

Brake disc weight before optimization is $5.68 \mathrm{~kg}$;

Disc brake torque after optimization is $171.58 \mathrm{~N} \cdot \mathrm{m}$;

Brake disc weight after optimization is $5.25 \mathrm{~kg}$.

As can be seen from Table 2, by optimizing the design, under the conditions of ensuring small temperature rise while braking strongly, disc brake torque increases to a certain extent, the weight of the brake drops at the same time, reducing the overall weight of the brake, achieving the purpose of optimization.

Table 2 The optimized contrast values of design variables of disc brake

\begin{tabular}{ccccccccc}
\hline Parameters & $D$ & $b$ & $d$ & $\rho_{0}$ & $R_{1}$ & $R_{2}$ & $\theta$ & Brake torque \\
\hline Initial values & $0.264 \mathrm{~m}$ & $0.0143 \mathrm{~m}$ & $0.0505 \mathrm{~m}$ & $3.1 \mathrm{MPa}$ & $0.061 \mathrm{~m}$ & $0.125 \mathrm{~m}$ & $60{ }^{\circ} \mathrm{C}$ & $128.71 \mathrm{~N} \cdot \mathrm{m}$ \\
$\begin{array}{c}\text { Optimized } \\
\text { values }\end{array}$ & $0.258 \mathrm{~m}$ & $0.0132 \mathrm{~m}$ & $0.0530 \mathrm{~m}$ & $3.35 \mathrm{MPa}$ & $0.086 \mathrm{~m}$ & $0.130 \mathrm{~m}$ & $52.1^{\circ} \mathrm{C}$ & $171.58 \mathrm{~N} \cdot \mathrm{m}$ \\
\hline
\end{tabular}

\section{Conclusion}

Aiming at the problem of existing brake optimization design that using shortest braking time and minimum thickness but not plan weight coefficient of sub-objective, the paper established multi-objective optimization model to arrive at minimum brake temperature rising and maximum brake torque. Simulation example showed that it can achieve ideal optimization result. As the disk brake is a complex integrated hydraulic and mechanical dynamics, there are many factors affecting brake effectiveness. Some parameters directly or indirectly affect system result and the impact is 
mutual. Therefore, its structure and mechanism should be thoroughly researched and discussed. The parameters should also be determined to establish more accurate model, which will be our next research focus in the future.

\section{References}

[1] Peijiang Chen, Study on vehicle braking performance detection system, Proceedings of 2012 IEEE Fifth International Conference on Advanced Computational Intelligence (ICACI), 2012, pp. 1009-1012.

[2] Lu Yinding, He Wenhua, Hou Mingyang, Yao Jiansong, Emulation and Experimental Study of Drum Dynamometer for Simulating the Vehicle's Road Braking, Proceedings of 2011 Third International Conference on Measuring Technology and Mechatronics Automation (ICMTMA), 2011, pp. 37-40.

[3] Zhang Xiaolong, Peng Jiankun, Xia Ping, Design of roadway test system for motor vehicle brake performance and its evaluation methods, Proceedings of 2010 International Conference on Computer, Mechatronics, Control and Electronic Engineering (CMCE), 2010, pp. 392-395.

[4] Qing Liyi, Xu Degang, Multiple objective optimized design for disc brake, Machine Design and Manufacturing Engineering, vol. 5, 2002, pp. 17-18.

[5] Ding Weidong, Liu Ming, Zhong Bingdi, Fuzzy optimal design for disk brake on construction machines, Construction Machinery and Equipment, Computer Simulation, vol. 11, 2001, pp. $19-21$.

[6] Song Ming, Liu Zhaodu, Liang Pengxiao, Co-simulation of ABS for cars in ADAMS and SIMULINK, Computer Simulation, Vol. 21, no. 10, 2004, pp. 163-166.

[7] Feng Jihe, Sun Wei, Ma Weibiao, Hu Yunhua, Application of Co-simulation technique in Fuzzy Control of vehicle semi-active suspension system, Journal of Academy of Armored Force Engineering, vol. 21, no. 3, 2007, pp. 40-44. 